eISSN 2444-7986

DOI: http://dx.doi.org/10.14201/orl201672.14242

Carta al Director

\title{
NOTA DEL EDITOR. LECTURA CRÍTICA DE ARTÍCULOS EN OTORRINOLARINGOLOGÍA
}

\author{
Editor's note. Critical reading of articles in Otolaryngology
}

\author{
José Luis PARDAL-REFOYO \\ SACYL. Complejo Asistencial de Zamora. Servicio de Otorrinolaringología. Zamora. España. \\ Director de Revista ORL. \\ Correspondencia: jlpardal@usal.es
}

Fecha de recepción: 10 de abril de 2016

Fecha de aceptación: 13 de abril de 2016

Fecha de Publicación: 30 de abril de 2016

Conflicto de intereses: Los autores declaran no tener conflictos de intereses Imágenes: Los autores declaran haber obtenido las imágenes con el permiso de los pacientes Política de derechos y autoarchivo: se permite el autoarchivo de la versión post-print (SHERPA/RoMEO) Licencia CC BY-NC-ND. Licencia Creative Commons Atribución-NoComercial-SinDerivar 4.0 Internacional (C) Universidad de Salamanca. Su comercialización está sujeta al permiso del editor

Nota del Editor

El pasado 9 de abril de 2016 se celebró en la Sala de Grados de la Facultad de Medicina de la Universidad de Salamanca el curso sobre «lectura crítica de artículos en Otorrinolaringología».

Curso acreditado por la Comisión de Formación Continuada de SACYL y organizado en el marco del Convenio de Colaboración de Bibliotecas de USAL y Revista ORL ${ }^{1}$.

Se dieron cita 21 asistentes de diversas especialidades. Los asistentes previamente recibieron por correo electrónico la documentación necesaria $[1,2]$.

\footnotetext{
${ }^{1}$ En http://www.revistaorl.com/:

http://media.wix.com/ugd/62037a_d598d5b7a7bd43b7b5 5eaeae7aea9ff3.pdf
}

El Dr. Pardal presentó a los ponentes, Dra. Helena Martín Rodero, Jefa de Bibliotecas del Área Biosanitaria de la Universidad de Salamanca y Dr. Luis Miguel Palomar Rodríguez, Jefe de Estudios de Atención Especializada del Complejo Asistencial de Zamora y Especialista en Medicina Interna. El Dr. Pardal expuso los objetivos del curso orientado a aprender a interpretar la calidad de los artículos científicos, a conocer la metodología para la lectura crítica, a mejorar los aspectos de revisión de los artículos en el proceso editorial y a valorar el papel del revisor en el proceso editorial. Se revisaron las secciones y tipos de artículo, las etapas principales del proceso editorial y los aspectos generales de la evaluación de artículos.

La Dra. Martín Rodero habló de recursos y herramientas útiles para todos los agentes 
implicados en el proceso de comunicación científica: autores, editores y revisores.

En primer lugar, realizó una selección de aquellos recursos de especial interés para los autores tales como recursos sobre escritura científica (manuales de estilo, diccionarios, glosarios terminológicos, guías y directrices sobre buenas prácticas y ética de la publicación, etc.), sobre edición y composición de textos, sobre servicios editoriales o programas de ayuda para la selección de revistas donde publicar. A continuación, abordó la utilidad de los sistemas de detección antiplagio y la eficacia de las listas de comprobación (checklists) para la evaluación de los aspectos de calidad formal de los artículos, destacando la página de la EQUATOR Network como fuente indispensable para su localización. Subrayó la importancia de las bases de datos para determinar la relevancia de los temas evaluados, la revisión de citas y referencias bibliográficas o la identificación de autores y revisores. También hizo referencia al soporte de los gestores de referencias bibliográficas y mencionó la necesidad de normalizar la firma científica mediante identificadores unívocos como ORCID ID o mediante la creación de perfiles de investigador. Por último señaló nuevas iniciativas en los sistemas de revisión por pares como los proyectos Akademia Karma, PeerJ, Rubriq o Publons, entre otros.

El Dr. Palomar hizo una primera exposición sobre el método de lectura crítica de artículos $C A S P e$, los niveles de evidencia según el tipo de artículo y, en particular, sobre el metanálisis puesto que el artículo seleccionado y analizado fue el titulado "Percutaneous and surgical tracheostomy in critically ill adult patients: a meta-analysis» [3].

Se realizó un primer trabajo en grupos de cinco alumnos utilizando como guía el instrumento para la lectura crítica de CASPe: «10 preguntas para ayudarte a entender una revisión» [2]. Tras el trabajo por grupos hubo un debate entre todos los asistentes con la puesta en común de los resultados del análisis de cada grupo para cada una de las preguntas. Finalmente, los asistentes realizaron un cuestionario tipo test y puesta en común sobre los conceptos más importantes abordados en el curso.

La tarea de la revisión de artículos científicos para su publicación en revistas científicas es difícil y no reconocida en el currículum. Es una actividad que supone un esfuerzo y compromiso adicionales. Una buena revisión es una oportunidad de mejora para el informe de investigación.

La lectura crítica de artículos tiene varias ventajas. Por un lado, ayuda a seleccionar artículos de calidad y a elegir las opciones de diagnóstico o terapéuticas más adecuadas basadas en la evidencia y, por otro lado, ayuda a mejorar la calidad de la revisión de los artículos dentro del proceso editorial.

Revista ORL y el Departamento de Bibliotecas de la Universidad de Salamanca en virtud del acuerdo de colaboración [4] seguirán en el esfuerzo de facilitar la formación en contenidos relacionados con el proceso de edición, documentación y metodología de investigación mediante cursos y talleres presenciales como online.

\section{AGRADECIMIENTOS}

Desde Revista ORL agradecemos al Decano de la Facultad de Medicina la cesión de la Sala de Grados para la celebración de este evento, a Luis Miguel Palomar Rodríguez su disponibilidad al realizar esta jornada y a Helena Martín Rodero su organización.

\section{BIBLIOGRAFÍA}

1. Putensen C, Theuerkauf N, Guenther U, Vargas M, Pelosi P. Percutaneous and surgical tracheostomy in critically ill adult patients: a meta-analysis. Crit Care. 2014;18(6):544.

2. Moher D, Liberati A, Tetzlaff J, Altman DG, The PRISMA Group. Ítems de referencia para publicar Revisiones Sistemáticas y Metaanálisis:La Declaración PRISMA. Rev Esp Nutr Hum Diet. 2014;18(3):172-81. Disponible en: http://renhyd.org/index.php/renhyd/article /view/114/99. [Citado el 10 de abril de 2016].

3. CASPe. Instrumentos para la lectura crítica: 10 preguntas para ayudarte a entender una revisión. [Internet]. Disponible en: http://www.redcaspe.org/herramientas/in strumentos. [Citado el 10 de abril de 2016]. 
4. Merlo-Vega JA, Ferreras-Fernández T. Colaboración Bibliotecas de la USAL y Sociedad Otorrinolaringológica de Castilla y León, Cantabria y La Rioja. Rev. ORL. 2016;7(1):65-6. Disponible en: http://revistas.usal.es/index.php/24447986/article/view/orl201671.13875. [Citado el 30 de abril de 2016]. doi:10.14201/orl201671.13875. 